\title{
Pierre Kunstmann, Achim Stein (éd.), Le Nouveau Corpus d'Amsterdam, Actes de l'atelier de Lauterbad, 23-26 février 2006
}

\section{G. Matteo Roccati}

\section{(2) OpenEdition \\ Journals}

\section{Édition électronique}

URL : http://journals.openedition.org/studifrancesi/5872

DOI : $10.4000 /$ studifrancesi.5872

ISSN : 2421-5856

\section{Éditeur}

Rosenberg \& Sellier

\section{Édition imprimée}

Date de publication : 1 mai 2011

Pagination : 147-148

ISSN : 0039-2944

\section{Référence électronique}

G. Matteo Roccati, «Pierre Kunstmann, Achim Stein (éd.), Le Nouveau Corpus d'Amsterdam, Actes de l'atelier de Lauterbad, 23-26 février 2006 ", Studi Francesi [En ligne], 163 (LV | I) | 2011, mis en ligne le 30 novembre 2015, consulté le 13 janvier 2021. URL : http://journals.openedition.org/studifrancesi/5872 ; DOI : https://doi.org/10.4000/studifrancesi.5872

Ce document a été généré automatiquement le 13 janvier 2021.

\section{cc) (†) $\odot$}

Studi Francesi è distribuita con Licenza Creative Commons Attribuzione - Non commerciale - Non opere derivate 4.0 Internazionale. 


\title{
Pierre Kunstmann, Achim Stein (éd.), Le Nouveau Corpus d'Amsterdam, Actes de l'atelier de Lauterbad, 23-26 février 2006
}

\author{
G. Matteo Roccati
}

\section{RÉFÉRENCE}

PIERRE KUNSTMANN, ACHIM STEIN (éd.), Le Nouveau Corpus d'Amsterdam, Actes de l'atelier de Lauterbad, 23-26 février 2006, Stuttgart, Franz Steiner Verlag, 2007 («Zeitschrift für Französische Sprache und Literatur, Beihefte», Neue Folge, 34), pp. 200.

1 Le Nouveau Corpus d'Amsterdam est «le résultat du remaniement du corpus de textes littéraires d'ancien français compilé par Anthonij Dees (...) et son équipe (...), corpus [qui] a constitué la base» (p.9) de l'Atlas des formes linguistiques des textes littéraires de l'ancien français (1987; cf. «Studi francesi», XXXII, 1988, p. 379). Le volume rassemble une dizaine de contributions, présentées lors de la rencontre de Lauterbad, au cours de laquelle avaient été examinés successivement «l'histoire du corpus d'Amsterdam, l'élaboration du nouveau corpus, puis différents projets et corpus historiques et, enfin, les acquis et perspectives dans ce domaine» (p. 7). Même si la rapidité de l'évolution des ressources informatiques a souvent rendu obsolètes les présentations et descriptions données ici, les considérations d'ordre méthodologique et les réflexions sur l'architecture des bases restent utiles. On retiendra en particulier: Pierre KUNSTMANN, Achim STEIN, Le Nouveau Corpus d'Amsterdam, pp.9-28, présentation de la base documentaire; Yves Charles MORIN, Histoire du corpus d'Amsterdam: le traitement des données dialectales, pp.29-50; Martin-D. GLESSGEN, Xavier GOUVERT, La base textuelle du "Nouveau Corpus d'Amsterdam»: ancrage diasystématique et évaluation philologique, pp. 51-84, bilan bibliographique et philologique des éditions utilisées dans la base; Lene 
SCHOSLER, Histoire du corpus d'Amsterdam: l'inclusion des manuscrits, pp. 85-100; Hiltrud GERNER, Constitution et évolution des corpus textuels et lexicaux à l'ATILF Interconnexion des ressources, pp. 101-109, sur les ressources relatives à la langue ancienne au laboratoire de Nancy; Pierre KunstMann, Gilles souvay, Dictionnaire électronique de Chrétien de Troyes (DÉCT), pp. 111-119; France MARTINEAU, Constanta Rodica DIACONESCU, Paul HIRSCHBÜHLER, Le Corpus «Voies du français»: de l'élaboration à l'annotation, pp. 121-142, projet canadien sur «l'évolution du français canadien, en partant du Moyen Âge» (p.121); Céline guillot, Alexei laVRentiev, Christiane Marchello-Nizia, La Base de Français Médiéval (BFM): états et perspectives, pp.143-152, projet de l'ENS-LSH de Lyon; David TROTTER, Habeas corpus ad testificandum: l'Anglo-Norman Dictionary et son corpus, pp. 153-158; Martin ELSIG, Esther RINKE, Les adverbes et l'inversion en ancien français. Le Nouveau Corpus d'Amsterdam soumis à l'analyse linguistique, pp. 159-180; Yuji KAWAGUCHI, L'état actuel de la dialectologie du français médiéval: le cas des chartes champenoises méridionales, pp. 188-200 (intervention au sein de la Table ronde: les corpus informatiques des chartes). 